\title{
A Preliminary Report on a New Substance which Remarkably Stimulates the Flocculation of Yeasts.
}

Sir :

It has been observed by the author that flocculation of yeasts is remarkably stimulated in the medium prepared from spent grains hydrolyzed with dil. acid. It is considered that in such a solution there exists a substance which stimulates flocculation of yeasts having no concern either with $\mathrm{pH}$ or with electrolytes which are usually regarded as flocculation-factors in colloidal solutions. These phenomena were not only observed in case of barley malts but also observed more or less in solutions prepared from wheat, rice, corn, and millet etc. hydrolyzed with dil. acid.

The method to estimate flocculation capacity is decided at present as follows.

The fermented wort prepared from definite malts in which brewers' yeast is cultivated at $28^{\circ}$ C. for $48 \mathrm{hrs}$. or the buffer solution at $\mathrm{pH} 4.6$ in which $1 \%$ press yeast is suspended, is replaced in a small test tube. And a certain amount of the sample is added.

The strength of flocculation power is measured by the time till the flocculation of yeast is distinctly observèd.

The medium shows no color reaction with $\mathrm{FeCl}_{3}$ nor biuret reaction. This flocculation facter can scarcely be dialyzed, but it is adsorbed with active carbon. In accordance with the fading of reddish brown color, this capacity decreases. It is insoluble in most solvents; mostly precipitated at $\mathrm{pH} 2 \sim 5$; perfectly precipitated at $30 \%$ saturation with ammonium sulfate; perfectly precipitated with heavy metals : soluble in alkalies; heat-stable; and it loses its capacity when ignited to ash. Because of these facts it is suggested that this substance must be acidic and relatively high-molecular.

An attempt was carried out to isolate the substance from the solution prepared fom spent grains hydrolyzed with $0.5 \% \mathrm{HCl}$ under pressure of $3 \mathrm{~kg}$. for 30 minutes. It was neutralized with $\mathrm{NH}_{4}$ $\mathrm{OH}$ at $\mathrm{pH} 4.6 \sim 4.8$, there was formed reddish brown precipitate which was dissolved with $\mathrm{NH}_{4} \mathrm{OH}$, and this procedure was repeated. Then it was saturated by $16 \sim 22 \%$ with ammonium sulfate, and at last was purified by dialysis against distilled water. Tiselius' electrophoresis $(\mathrm{pH} 7.8$ phosphate buffer, ionic strength $0.1, \frac{d E}{d x}=1.6$ volts $\mathrm{cm}^{-1}$, time 90 minutes, temp. $12^{\circ} \mathrm{C}$.) showed that it gave a simple mobility (about $4.6 \sim 4.8 \times 10^{-8} \mathrm{~cm}^{2}$ volt-1 $\mathrm{sec} .^{-1}$ ).

Actually in some cases it showed a beautiful jewel arrangement. A direct proportion exists between its color and concentration. By adding the substance in concentration of $3 \times 10^{-0}$ into fermented wort or in concentration of $1 \times 10^{-0}$ into yeast suspension vigorous flocculation of yeast took place within 30 minutes

The author is very grateful to Prof. Kin-ichiro Sakaguchi for his kind guidance and criticism and also to Mr. Kan-ichi Asami for his Kindness and the keen interest shown to the author during this study.

(This report was read on May 4, 1951 in the Annual Meeting of Agricultual Chemical Society of Japan). 